\title{
Erratum to: Biceps Detachment Decreases Joint Damage in a Rotator Cuff Tear Rat Model
}

\author{
Stephen J. Thomas PhD, ATC, Katherine E. Reuther BS, Jennica J. Tucker BS, \\ Joseph J. Sarver PhD, Sarah M. Yannascoli MD, Adam C. Caro DVM, \\ Pramod B. Voleti MD, Sarah I. Rooney MSE, David L. Glaser MD, \\ Louis J. Soslowsky PhD
}

Published online: 11 July 2015

(C) The Association of Bone and Joint Surgeons (B) 2015

\section{Erratum to: Clin Orthop Relat Res (2014) 472:2404-2412 \\ DOI 10.1007/s11999-013-3422-8}

Due to an error during our data collection of ground reaction forces, several sections of our published study, "Biceps Detachment Decreases Joint Damage in a Rotator Cuff Tear Rat Model" are incorrect. We wish to correct our results for shoulder function measurements and revise our figure legend.

We would like to modify several sections of our study based on the corrected data. The first sentence in the Results of the abstract should read: The supraspinatus, infraspinatus, and long head of the biceps group had a decreased change in braking and vertical force.

The Conclusions section of the abstract should read: Detachment of the long head of the biceps tendon in the presence of a posterior-superior cuff tear resulted in less joint damage to the remaining structures.

Due to our data collection error, the results in our study have changed. The first paragraph of the Results section in the body of the text should read: The additional detachment of the long head of the biceps in the presence of a supraspinatus and infraspinatus detachment demonstrated a decreased change in braking and vertical force compared to

The online version of the original article can be found under doi:10.1007/s11999-013-3422-8.

S. J. Thomas, K. E. Reuther, J. J. Tucker, J. J. Sarver,

S. M. Yannascoli, A. C. Caro, P. B. Voleti, S. I. Rooney,

D. L. Glaser, L. J. Soslowsky $(\square)$

McKay Orthopaedic Research Laboratory, University of

Pennsylvania, 424 Stemmler Hall, 36th Street and Hamilton

Walk, Philadelphia, PA 19104-6081, USA

e-mail: soslowsk@upenn.edu; Soslowsk@mail.med.upenn.edu the biceps being left intact (Fig. 1). Specifically, rats in which a biceps tenotomy (95\% CI $=3.65$ to 2.29 ) was performed did not have a different change in medial/lateral force $(\mathrm{p} \geq 0.2, \mathrm{ES}=-0.06)$ than those with an intact biceps (95\% CI $=3.95$ to 2.17 ). The rats with a biceps tenotomy $(95 \% \mathrm{CI}=3.35$ to -0.45$)$ did not have a different change in propulsion force $(\mathrm{p} \geq 0.5, \mathrm{ES}=-0.13)$ compared to those with an intact biceps $(95 \% \mathrm{CI}=3.02$ to $0.74)$. The rats with a biceps tenotomy $(95 \% \mathrm{CI}=-0.10$ to $-2.41)$ did have a decreased change in braking force $(\mathrm{p}=$ 0.006 , ES $=1.09)$ at 28 days compared to those with an intact biceps (95\% CI $=-2.88$ to -5.86 ). The rats with a biceps tenotomy $(95 \% \mathrm{CI}=-0.66$ to -14.88$)$ had a decreased change in vertical force $(\mathrm{p}=0.04, \mathrm{ES}=0.325)$ at 7 and 42 days compared to those with an intact biceps $(95 \% \mathrm{CI}=-6.25$ to -18.67$)$. This suggests that rats with a biceps tenotomy had minimal change in shoulder function over time compared to those that did not receive a biceps tenotomy.

The Discussion section of our paper should reflect our revised analyses. The first two sentences in the third paragraph of the Discussion section in the body of the text should read: We demonstrated that shoulder function, as measured by a change in ground reaction forces from baseline, had minimal differences in the supraspinatus and infraspinatus group compared to the supraspinatus, infraspinatus, and long head of the biceps group. Specifically, the supraspinatus and infraspinatus group had an increased change in braking and vertical force.

Also, the first sentence in the last paragraph of the Discussion section in the body of the text should read: In conclusion, additional detachment of the long head of the biceps tendon in the presence of combined supraspinatus and infraspinatus tears in this animal model had minimal 

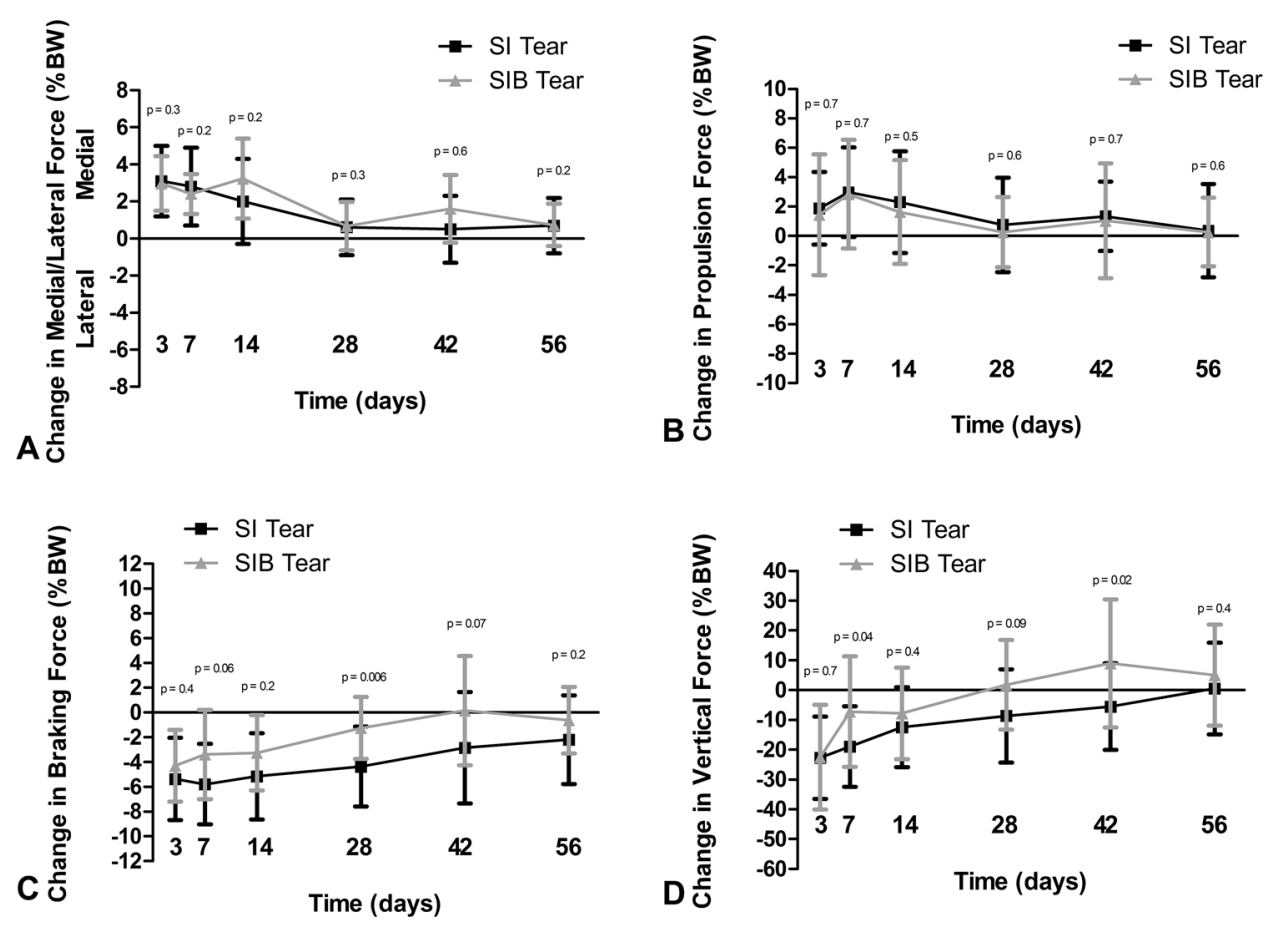

Fig. 1A-D There were no differences for the change in medial/lateral force (A) or propulsion force (B). The SIB group had a decreased decreased change in vertical force (D) at 7 and 42 days after detachment compared to the SI group. Data are shown as mean with SD. $\mathrm{BW}=$ body weight.

changes in shoulder function and improved subscapularis tendon properties (mechanical and structural) and did not affect the glenoid cartilage properties.

Finally, the revised Figure Legend is given in this erratum.

The authors apologize for the error. 